\title{
THE FORESTRY PROFESSION AND THE PUBLIC ${ }^{1}$ By K. G. FENSOM ${ }^{2}$
}

The theme of my paper-"The Forestry Profession and the Public"is the theme of this 49th annual meeting of the Canadian Institute of Forestry. It is an honor and a privilege to have been given this assignment, although there are many others who, by reason of their specialized experience, are better qualified to do justice to this topic. However, this is merely a comment not an apology. I am glad to have this opportunity to place my views before you, and to stress the need for positive and imaginative action in a field that has always been difficult for the forester.

Public education is synonymous with public relations, and it might be advisable to define it so that there will be no misunderstanding as to what is being discussed.

First, I would like to stress that I am not going to try to analyse techniques of using such publicity media as books, pamphlets, moving pictures, radio, plays, television, exhibits, advertising mats and billboards, film strips, slides, photographs and magazines. All these and other media have been employedsome quite extensively, others on an exploratory and tentative basis. I imagine that there is general agreement among foresters that these media can and should be utilized to the fullest extent possible, but that there is equally general realization that a limiting financial factor makes it impossible to do more than can be well done with presently available funds. Since it would not appear that greatly increased funds will be forthcoming for these purposes in the immediate future, a discussion of what might be done to increase the flow of publicity through these various media would be unrewarding.

Second, I would like to make it clear that I am not planning to discuss the kind of public education which has been so well done by the Canadian Forestry Association and its provincial affiliates in Quebec, Ontario and British Columbia. As was stated by President Wallace A. Delahey at the annual meeting of the C.F.A. in March, 1955, at Montreal "the Canadian Forestry Association is dedicated to education of the Canadian public on the importance of renewable natural resources, with special emphasis on forest fire protection." No other body or group has done a comparable job as regards education of the public about fire protection, tree planting and tree farming. No other body or group at the national level has done a comparable job in the tremendously important field of youth education in forestry. The Association's tree planting car, its Junior Forest Wardens, its 4-H Clubs, its free film libraries, its Forest Conservation Week, its postwar competition, its monthly magazine, its teachers' and camp wardens' workshops are established and productive activities. Nothing can detract from the value of this work; nothing should be allowed to interfere with its continuance and expansion.

In fact, and perhaps partly because of the good work done by the Canadian Forestry Association, many persons think of forestry only in terms

1 Theme address at the annual meeting of the Canadian Institute of Forestry, Toronto, Ontario, October 22, 1957.

'Superintendent, Forest Products Laboratory, Vancouver, B.C. 
of fire protection or tree planting, and of a forester as one whose chief responsibility is to detect and put out fires or plant trees. These specific phases of forestry needed to be emphasized, and they still need to be emphasized. However, another urgent need-and one that has been largely neglectedis education of the public in forestry professionalism. Without this broad understanding of forestry and foresters and all that forest management means and implies, the public will not be sufficiently informed to be able to assist in establishing forestry as it can and must be established if the aims of forestry are to be completely realized.

It is the purpose of this paper to show that it is largely the responsibility of the individual forester and his professional body, the Canadian Institute of Forestry, to provide this type of public education.

Every person has public relations in the sense of human relations. These may be good, bad or indifferent, but they are as inevitable as death and taxes. No one, no matter how independent in spirit and outlook, can live in a vacuum completely divorced from family, friends, colleagues, business associates and acquaintances. For the individual, life is a composite of personality conflictions and meshings-there being usually an excess of the latter when there is a keen sense of social obligation and responsibility in respect to one's personality adjustment. As far as the individual is concerned, public relations are integrated and interwoven with all his actions as he assumes different roles at different times and as his actions are directed first towards one objective then towards another. Thus it is within the power and control of the individual to consciously direct his activities into narrow channels of self-advancement. Alternatively, it is within his competence to further his own interests within a framework of also furthering the interests of his business classification or profession. This latter type of effort may be dictated by ethics, morality, idealism or down-to-earth practical considerations, but, whatever its inspiration, it is the kind of individual public relations that is most productive. Forestry, as much if not more than any other profession, must have, not a few but many, individuals making significant contributions in the area of public relations if the objectives of forestry are to be achieved. A number of foresters have made such contributions but more have not, and I believe that one of the main reasons is not that too many foresters are lacking opportunity because of being buried in the woods, or not that too many are unwilling to assume responsibilities in respect to talking or writing about forestry, or not that too many do not have the ability to communicate in other than professional or scientific jargon. These are certainly reasons why many foresters have failed to exercise their personal public relations responsibilties, but another reason is that foresters frequently lack dynamic conviction of their own importance as citizens. This feeling stems from the fact that foresters, with some few but notable exceptions, have not made their presence felt in citizenship and community activities. What Raymond R. Tucker, Mayor of St. Louis, formerly Head of the Department of Mechanical Engineering, Washington University, St. Louis, wrote about engineers in the January, 1956, issue of Civil Engineering can also be said about foresters-"he adheres too closely to his own speciality and in greater or lesser degree neglects his duties as a citizen". 
The other kind of public relations of which I am going to speak, and in the exercise of which the public is instructed and educated, is organized public relations. I suppose that the organized efforts of the medieval guilds to establish a demand for certain hallmarked crafts could be called public relations, but this is not public relations as I understand its application today, although the final objective is often the same now as it was then, namely, to convince people of the merits of a product. Public relations as an integrated function of management goes beyond the bare bones of promotion. It probes into motives, causes and effects. It takes account of the attitudes and reactions of the public. It is realized that its grass roots are in the community and that it evolves through the contacts of individuals one with the other. Above all, its purposes are identified with the interests of the people, and its objectives are to gain public understanding and goodwill.

Public relations is more than just publicity. Publicity more often than not is favorable whether or not the idea, policy or product being publicized merits public approval and favor. Publicity is the manipulation of public opinion, and sometimes this manipulation has very little relation to the truth. Proper public relations involves integration of acts and purposes and identification with public welfare. Such public relations has nothing in common with propaganda, ballyhoo, ill-considered press agentry, phony promotion or cheap publicity.

A surprising feature about public relations is that, although specialists have been engaged in developing worthwhile humanizing public relations programs since the turn of the century, its widespread use as an effective moulder of public opinion in the best interests of the community is of comparatively recent origin. During World War II, for instance, the urgency of many facets of the war effort, such as food and gasoline rationing, civil defense, price controls, blood donations, etc., was stressed through the medium of planned public relations to an extent that would not have been dreamed of forty years ago. Likewise public relations is today more than ever employed to accentuate the common interests of employers, workers and consumers.

The significance of public relations to the profession of forestry-both organized national public relations and individual personal public relations -is that, if ever the public of Canada is to become thoroughly familiar with the purposes of forestry, it will be through the medium of a well-planned program and intensive participation on the part of many foresters. I am sure that all foresters, no matter what may be their diversified opinions regarding method, are agreed that unless the public be so informed it will not be possible to realize the ultimate in sustained yield forest management. If the professional forester cannot make his principals understand what he is trying to do over the long term he will achieve only limited objectives. If the public cannot be made to understand about forestry there will be no voice of the public making itself felt in federal and provincial legislatures. There is by no means a black-out of forestry understanding in Canada at the present time, but neither is there that complete understanding, sympathy for, and receptivity to forestry ideas and issues without which the maximum in forestry potential can never be realized. 
Some of the reasons for this lack of public understanding of forestry are obvious. The profession of forestry in Canada is a comparatively young profession. It does not much pre-date the founding of the Faculty of Forestry at the University of Toronto in 1907. Being young, its objectives and aims are not as yet completely solidified. It has jelled greatly during the past fifteen years, but mostly and rightly it has been more preoccupied with searching for basic knowledge than with trying to interpret these fundamentals to the public. The profession of forestry is not a thickly populated profession as is medicine or engineering. Since foresters constitute only about .01 per cent of the population of Canada they are thinly spread-and often inconveniently located-in respect to making numerous contacts with the public.

The profession of forestry as a profession is not enormously wealthy. With few exceptions salaries are not commensurate with those earned by physicians, chemists and engineers, and hence it is relatively difficult to finance professional projects. These and other reasons have acted as a brake and deterrent to the adoption of an effective public relations program. In fact, the profession has no program period, effective or otherwise. What has been done in this field has been done by individual foresters acting on their own initiative, or it has been done by foresters in conformance with their job requirements as members of the staffs of public relations divisions of provincial governments, or it has been done by foresters and others in the employ of bodies such as the Canadian Forestry Association and its British Columbia, Ontario and Quebec affiliates, the Canadian Pulp and Paper Association, and various associations, committees and councils. It has also been done by a very few foresters as an integrated part of the overall public relations program of certain companies, chiefly pulp and paper companies. It has never been done, except in fortuitous fashion, by the national professional body, the Canadian Institute of Forestry.

Before proceeding with this discussion, it might be noted that the profession of forestry is not unique as regards criticism of its public relations. Of all the professions probably the medical profession has done the best job of dramatizing itself-the rigorous, lengthy, intensive and costly training required of its undergraduates; the tremendous network of research which is constantly being carried on in the interests of the public; the high status of the doctor in the community; and the demanding nature of a doctor's work in the service of mankind. Yet even in the very powerful and wealthy medical fraternity all is not well as witness the following quote from "The Doctor, his career, his business and his human relations", by Stanley R. Truman, M.D.- "the threat of socialized medicine has awakened the medical profession from a state of self-complacency to an awareness that the public has been dissatisfied with medical care. We have lost a great deal of our public understanding. Because the individual rarely approaches the doctor with adverse criticism, doctors are unlikely to realize the extent of the layman's dissatisfaction with the practice of medicine." Carlton S. Proctor, President of the American Society of Civil Engineers, in his annual address at Denver stated"Engineers as a professional group have failed to exercise the leadership and direction so long needed. We have failed in still greater degree to accept our special responsibilities in public affairs." Victor E. Munice, Malcolm Klein 
and Dr. Nathan Maccoby, in the September, 1954, issue of Chemical Engineering stated-"The man on the street has a pretty high opinion of chemical engineers and chemical engineering. The only trouble is that he has no idea of what a chemical engineer is or what he does." The fact of the matter is that all professions are concerned about their public relations, the older and better organized professions no less than forestry, the reason obviously being. that it is realized that professions as well as industrial enterprises must function in the public interest and must enjoy public confidence and understanding if they are to contribute to overall progress.

When something needs to be done that has not been done, it is always a good idea to look at what has already been accomplished by others, and to borrow from and adjust these established and proven programs. What has been done by the physical scientists provides one of the best examples for forestry. They have told their story, especially in this atomic age, in terms of dramatic human interest and public benefit, and in so doing they have gained the confidence and respect of the public. In this kind of climate it is not too difficult to create progressive and informed public opinion. The story of forestry can and should be similarly told, not by means of razzle-dazzle propaganda, but by enthusiastic presentation of forestry facts in an informative and entertaining way. Both the individual forester and the Canadian Institute of Forestry should be seizing every opportunity to explain all about forestry -the theory of forestry, the inter-related sciences and their place in the forestry pattern, the type of education received by a forester, the challenging problems of research, the accomplishments of the profession and the tremendous variation in the work activities of foresters. There is no dearth of material for such presentation to the public-the problems are how to compile it, how to organize it, how to make it interesting, and how to sustain it.

At the beginning of this paper I stated that public relations are a difficult problem for foresters. They are a problem not because foresters lack enthusiasm. I have heard many foresters talk eloquently and well to non-foresters about their professional activities during the course of casual informal conversation. But too many of these same foresters, when giving formal addresses or when writing for the purpose of inspiring public interest, fail to create the same kind of atmosphere and understanding. And they fail because their language is too technical, too scientific, and not properly adjusted, either in appeal or in terms of dramatic content, to the needs and interests of the audience being addressed. Sometimes there is too much concern with broad principles rather than with unusual and attention-holding facts. Because of these failures, much forestry writing and public speaking is non-effective. It is not understood. It does not create interest, and it does not, therefore, advance the cause of forestry.

It is a forester's professional obligation, in addition to his technical responsibilities, not only to talk to and write to the public about forestry, but also to learn how to do this in such a way as to produce the desired result. The percentage of foresters who are presently engaged in this type of activity is low. The percentage who are doing it with telling effect and emphasis is very low, so low in fact that months go by without a single major pronouncement 
or significant public relations contribution from any forester in any part of Canada. Unless this forestry silence can be filled in with noted and notable noise, the public of Canada will continue to be inadequately informed about forestry.

It is easy to say this should be done or that should be done-not so easy to define the how of it. It is not too much to hope that eventually every forester will be in public relations in some manner, shape or form, and that the total effort will be greater and more distributed than it is today. Nor is it too much to hope that more foresters will become expert in the skills that are required, especially those with above average aptitudes for this type of undertaking. There is no relationship whatever between being a good forester in the technical sense and being a good forester in the discharge of public relation responsibilities. Relatively few people have the natural ability to talk and write in popular style. Nor are many equipped to do public relations by reason of the training which they have received.

Not many foresters, therefore, have the potential to be outstanding in these specialized skills, but my point is that even this potential is far from being realized. How, then, can the varying potentials of all foresters, depending on their opportunities, be mobilized?

Public relations should, $I$ believe, be part of the undergraduate education of all foresters. I know that curricula at forest schools are already jam-packed, that nearly every suggested change has to do with additions rather than deletions and that there is almost complete exclusion of any recommendations for stream-lining and condensation. I wish, therefore, that this could be a suggestion in the category of a deletion, for, if it were, it would be that much easier to incorporate. Nevertheless, there is an alternative to introducing another course into already crowded curricula, and that is to integrate public relations into all courses on general forestry, silviculture, fire protection, forest influences, forest policy, silvics, economics, and so on. It is suggested further that this integration be preceded by some general lectures descriptive of the theory of public relations, and followed by practical exercises in application and interpretation. This kind of set-up would presumably provide instruction as to the significance and importance of public education, what tools are used, social implications and human relationships, what are the elements in each compartment of forestry on which there should be special emphasis, and how these elements should be described to different sections of the public and through what media.

If undergraduates were so instructed, there would be more likelihood of the maximum public relations potential of foresters being realized. Not only would they feel that they had more responsibility in respect to explaining to the public about trees, forests and forestry, but they would also be better equipped to assume this responsibility, and being better equipped they would have more confidence. Perhaps the most valuable assets which they might acquire would be the ability to talk and write two English languages-one the language of technical forestry, the other the language of popular equivalents.

Actually, language is one of the biggest roadblocks in forester-general 
public communications. Perhaps a contributing reason is a weakness in our high school English and later in our liberal arts education at the university, but whether or not this be so, instruction in public relations at the university level would help immeasurably.

Another roadblock is created by the straight line approach, by a tendency to present concepts in terms of principles rather than in terms of examples. The bare bones of forestry principles are austere and often rather uninviting, besides being difficult for the public to understand. But those principles can be vitalized and made simple and intriguing by stories and experiences which, without spelling out the related concept in so many words, tend to suggest it. This is the circuitous approach, but it is particularly effective because the public is persuaded rather than bludgeoned. When a concept is presented in terms of examples, it is more apt to stick. For instance, it is possible to talk about the benefits of pruning on stand improvement over a given rotation period until one is blue in the face without the public being any wiser, any more interested or any more involved in final policies. But do some pruning, cut some sawlogs or peeler logs from a pruned and an adjoining unpruned stand, and show that there is a fifty per cent gain in lumber and veneer recovery values, and immediately the public-that is, that part of it which we are trying to influence by this specific example-is educated about the benefits of pruning. The story and experience are understood and the concept is deduced without a word being said about stand improvement.

Although this is a circuitous technique it is predicated on factual information accumulated by means of investigation and research. The trick is in finding or making examples to fit the concept and presenting them in the right words to the right groups. I do not think that this technique is used consciously on a sustained basis in any forestry public relations program in Canada. If it were used, I believe that there would be much greater understanding of forestry. I also believe that these techniques can be taught and demonstrated, and that in the process of so doing this formidable roadblock might become less formidable.

What about the graduate forester? How can he become more adept and better equipped to tell the story of Canadian forestry to the public of Canada? Enthusiasm and willingness to carry some of the load are parts of the answer, and I am suggesting that recruitment of those who are willing to be classified in this category by the Canadian Institute of Forestry on a nationwide basis might be a first step. I am a great believer in letting people stand up and be counted. When like looks at like a warm feeling of sharing in a worthwhile cause and a climate favorable to achievement are generated, and I am confident that many foresters would wish to be identified with any cause that is good for forestry.

Perhaps each member of the group would be willing to commit himself to give one address about forestry in a year to any organized group of citizens other than foresters, or to write one popular article, or to organize one practical demonstration, or to participate in county, provincial or federal affairs, or to associate forestry with some community enterprise by active participation in it. A widespread willingness to contribute in any one or all of these activities 
would be indicative of a very healthy condition in the profession, but unfortunately it would not necessarily be indicative of a high degree of effectiveness. Unless willingness is matched by equivalent ability, there will be less than the best possible performance, and consequently less than maximum results.

Some foresters are hesitant about indulging in public relations because they think they lack pertinent skills and training. It is suggested that some, at least, of these skills and training could be acquired gradually from a public relations pool operated from national C.I.F. headquarters in Toronto. The idea would be that individual foresters would, in accordance with an agreed plan, keep the national office advised in respect to each public relations gambitnot just the bare contents of a paper or article, but a full description of the circumstances, the reasons that prompted the effort, the reactions to it, the central themes of the message, the thinking behind its presentation, and the manner of interpretation to the public. It would be the responsibility of the national office to classify and catalogue each example, mimeograph or multilith it, and distribute it to all members of the C.I.F. In this way, each member would constantly be benefiting from the experience and know-how of every other member. Some of the material so supplied could undoubtedly be used as effectively in other parts of Canada as in the locality where it originated. Some of it could be adjusted and changed to meet the often unique requirements of specific situations. Some of it would be suggestive of novel techniques, methods of enlisting co-operation, and demonstrations of popular language use. Assuming that most, if not all, foresters in Canada who would be making tangible efforts in public relations are members of the C.I.F., and assuming again that all these foresters would be willing to file their contributions with the national office, then the proposed public relations pool would be a more or less complete record of the public relations activities of the forestry profession in Canada, and I do not see how individual foresters could fail to benefit or be inspired by having this complete record at their disposal. Even if the public relations pool were less than complete, it would still provide valuable instruction and advice; and it would keep ideas percolating.

Another means of providing instruction would be through the medium of correspondence courses in forestry public relations. Such courses could be organized and prepared by the staff of forest schools in co-operation with other university departments. Or alternatively these courses could be prepared by one or more specially qualified individuals-not necessarily university personnel-on a contract basis, and subsequently administered, operated and adjusted from time to time by the forest schools. Granted this would be a formidable undertaking, but it would not be an impossible one.

As far as the individual forester is concerned, I might sum up by reemphasizing the vital importance of his participation in some form of public relations. Such participation would be to his personal advantage in that it would increase his prestige in the community by creating better understanding of what he is trying to do. It would give him better job security and probably a better salary. In addition to these personal advantages, it would give him the satisfaction of having contributed to the advancement of the profession 
by making it easier to attract competent people to carry on the work of the profession. Another satisfaction would be his awareness of having increased public confidence in and sympathetic support for forestry.

I believe that the cause of forestry will or will not be assisted by public relations in direct relationship to the degree of participation of the individual forester. However, there are activities that could be undertaken in the interests of forestry which are beyond the scope of the individual. The profession of forestry is not sufficiently wealthy to engage the services of public relations specialists at large fees as do the medical and some other professions. But most of the pulp and paper companies and some of the larger lumber companies have public relations departments organized for the purpose of promoting the company's interests and objectives, both internally in respect to its staff, and externally in its relations with the public. These activities are seldom carried on by foresters and hence are beyond their influence except indirectly. This may not be the reason for lack of integration of these programs, but whatever the reason, there would appear to be relatively few consistent and correlated educational projects in the direction of explaining and interpreting forestry. This kind of education might well be incorporated in more company public relations programs for the sound business motive that the success of the company is very closely related to the success of forestry. My point in this connection is not that private industry has not made excellent and unselfish contributions in the general cause of forestry, but that the effectiveness of these contributions might be greatly increased if they were correlated, spaced and channelled towards the public in accordance with some co-ordinated plan.

Speaking again of effort beyond the purlieu of the individual forester, I believe that some of the greatest impetus towards general understanding and appreciation of forestry has been provided by royal commissions. In recent years there have been royal commissions in Ontario, Saskatchewan, Newfoundland and British Columbia. Innumerable briefs have been prepared. Millions of words of discussion and argument have been recorded, much of which has been abstracted and published in daily and weekly newspapers, trade journals, news letters and special bulletins. There have been many related speeches, a great deal of editorial writing, and prolonged controversies both as regards the hearings and the findings. All this has stirred up public interest, and in my opinion has created much understanding of the ramifications of forestry-not just fire protection or tree planting or erosion or forest management licences, but the whole broad field of forestry-to a degree that could not and cannot be equalled by any other type of activity. A royal commission does not have a public relations objective, but public relations are as sure and certain a development as are its industrial, political and professional recommendations.

This was particularly obvious in British Columbia where Chief Justice Sloan's Royal Commission on Forestry functioned during the past two and one-half years, and where an enormous amount of continuous, sustained and spontaneous publicity followed the hearings. In his report, released in September, 1957, Chief Justice Sloan recommended that, because of the 
changing pattern of the forestry picture and the consequent need for disinterested and impartial periodic review, a royal commission should be appointed every ten years. These periodic reviews would unquestionably contribute towards constantly improving forest administration. But indirectly, they would also contribute towards better public understanding of forestry which, in turn, would make the ultimate objective of forest management that much easier of accomplishment. Both from a technical and a public relations point of view royal commissions, appointed at regular ten-year intervals in all the forested provinces of Canada, would pay for themselves many times over.

Well, gentlemen, those are some of my ideas in respect to the forestry profession and the public. I fully expect that these ideas will be dissected and picked to pieces in profitable discussion. I hope, too, that because of the contributions which you will make at this annual meeting, there will be created a greater understanding of the significance of public relations in forestry affairs, a conviction that things are not being done in this field that could be done, and an incentive that will spark new undertakings and action. 